\title{
Governance and Reporting in a Complex Global Environment
}

\author{
Claire Richards ${ }^{1, *}$, Mary Ann Reynolds ${ }^{2}$, Jesse Dillard ${ }^{3}$ \\ ${ }^{1}$ College of Business Accounting Faculty, Zayed University, United Arab Emirates \\ ${ }^{2}$ College of Business Accounting Faculty, Sultan Qaboos University, Oman \\ ${ }^{3}$ College of Business Accounting Faculty, Central Florida University, United States
}

Copyright $\mathrm{O} 2016$ by authors, all rights reserved. Authors agree that this article remains permanently open access under the terms of the Creative Commons Attribution License 4.0 International License

\begin{abstract}
The purpose of this paper is to explore whether there are extant mechanisms that are utilized to meet the challenges of diverse corporate governance needs in modern global society. We adopt the nonlinear lens utilized in complex adaptive systems. The examination is advanced using three examples drawn from published academic research. The three examples selected allow consideration of differing levels of analysis, regions and entity types. Levels of analysis include societal, institutional and firm. Regions include Asia Pacific, United States and international. The governance types are governmental, charitable and corporate. Distinct world views are represented by considering the holistic worldview of the indigenous Maori as well as an emerging CSR agenda for an international corporation. Diverse objectives are exemplified by the inclusion of required not-for-profit reporting.
\end{abstract}

Keywords Governance, Reporting, Corporate Social Responsibility

\section{Introduction}

Global society faces challenges in the complex, interrelated environment of the $21^{\text {st }}$ century. Neither countries nor corporations function in isolation, and global concern for the environment and well-being of world population's present challenges to all. We question whether we, as a global society, have existing mechanisms to meet these challenges. This paper will consider examples that offer possible guidance.

Working models in previous centuries were based on Newtonian science and Cartesian rational, mechanistic, reductionist models. This western philosophical view dominates attempts to explain the world in the physical sciences. Developments in physics of different scientific models allow for a different understanding to emerge.
Quantum theory, chaos theory, and complexity theory allow for a more holistic world-view and the possibility of different solutions to global challenges.

Mukerji notes that renaissance thinkers like Bruno, Galileo, Erasmus, Boyle, Kepler, Copernicus, Bacon and Newton instituted causal science and the experimental method. Descartes further introduced a model that was based on the "fundamental distinction between nature and humans, between matter and mind, between the physical world and the social/spiritual world [1]." The social sciences attempted to legitimate their standing as science by adopting the rationalist scientific model. This led to the exclusion of the holistic world-view of eastern philosophies and indigenous peoples. The question raised by Mukerji and other scholars was whether the rational causal model was necessarily useful in understanding those cultures whose worldview and thus, the social sciences, have a different underlying paradigm.

Eastern philosophies, as well as the world-views of many indigenous peoples, are harmonious with the newly acknowledged scientific paradigms of quantum, chaos and complexity. Holistic rather than dualistic, all things are seen as connected with mutual impacts. In this world-view, all things have intrinsic value. This holistic approach was put forward by Schumacher [2] in his book, Small is Beautiful: a Study of Economics as if People Mattered. Daly et al.[3] incorporated this view in discussions of economics of the planet. Scientists and writers in many disciplines followed with questions of sustainability for not only physical resources but also for social structures and cultures. Researchers and theorists began to look more broadly for possibilities and explanations. In western business writings, these concerns emerged in stakeholder theory and accountability. Accounting literature examining social responsibility and sustainability is reviewed by Gray [4][5], Mathews[6], Bebbington [7] and Bebbington et al.[8] among others. These writers placed emphasis on the environment and sustainability as well as on accountability to interests outside corporate ownership. This emphasis is congruent with the stakeholder theory approach in corporate 
governance literature. In eastern thought, we see Bhutan's national happiness index as one exemplar and the bio-centric cosmogony of the indigenous Maori in New Zealand as another. Further, Bolivia and Ecuador give legal standing to nature.

The question in this paper is, "Do we have tools that attempt answers to the emerging societal and physical challenges of the $21^{\text {st }}$ century?" We will explore the view that leadership and accountability through governance and reporting can make an important difference. In global society there are many types of incorporated organizations or entities. We will consider a range of organizations that operate in society. All are part of the "whole" and should be accountable to global society for their decision and outcomes. Thus, they must have governance guidelines and reporting.

The paper proceeds as follows. We will first discuss governance and accountability (Section 2), and complexity and interconnectedness (Section 3). We will then examine three empirical examples of governance and reporting structures (Sections 4-6) with different approaches to meeting the complex challenges of present-day entities. These include: 1) governmentally required reporting from New Zealand; 2) not-for-profit required disclosures in the U.S.; and 3) voluntary reporting by a publicly traded corporation. Section 7 concludes.

\section{Governance and Accountability}

Bob Tricker[9] states, "all corporate entities, including profit-oriented companies, both public and private, joint ventures, cooperatives, and partnerships, and not-for-profit organizations such as voluntary and community organization, charities, and academic institutions, as well as governmental corporate entities and quangos, have to be governed." We will adopt this inclusive view of corporate entities. Entities incorporate to function within society in order to accomplish a specific purpose and objectives. Governance has been defined as power over the organization. Thus, to both set strategic objectives and to monitor or supervise activity, governance has a critical role. Many governance bodies are referred to as boards with the members being considered directors. In our discussion, we will use this reference. Globally there are a number of common board models. Structure varies but is often based on local practice or on requirements for listing on exchanges or government registries. The two basic boards of governance types can be described as unitary or two-tier, each having its particular strengths and weaknesses. The unitary board includes both executive and outside directors in its structure. Executive directors are drawn from upper management in the organization while outside directors are held to be independent. The two-tier board requires a separation of the executive board, which may be comprised from management and have management responsibilities, and outside directors who provide the monitoring or supervisory function. The requirement for a two-tier board in Germany, and recommended in the European Union, specifically mandates that one-half of the supervisory board members come from labor. Taiwan and China also use the two-tier structure, while the Dutch governance model requires the supervisory board to be tri-partite, including representatives from labor, capital, and society. The strength of this model is the diversity of viewpoints brought to bear on the challenges facing the entity.

The purpose of the board, regardless of its structure, is to offer direction and supervision. Current practice admits accountability to wider stakeholder groups including employees, the wider community and the environment. Objectives set by the governing body can be met through effective implementation by management. Successful implementation requires accountability through reporting guidelines and public reporting. From a systems perspective this is part of the requisite feedback loop.

\section{Complexity and Interconnectedness}

Complexity theory, which views the world as interconnected and holistic, has itself evolved in the theory of complex adaptive systems (CAS). CAS theory further posits that diversity is essential for adaptation and change. In 1947, the physicist Prigogine established the role of variation, fluctuations and emergence in systems (cited in Boulton ${ }^{10}$ ). Further, uncertainty led to emergence and evolution. This led to the notion of the central role of variation in systems. Boulton[10] states, "Complexity theory has arisen, over more than half a century, out of the work of many scientists and social scientists who seek to investigate the implications of embracing the world as messy, interconnected, open to influences and change, able to learn - a world more like the river Heraclitus envisaged, and indeed more like the world we inhabit." Further, things interrelate, affect each other in a messy, complex, systemic fashion, and variation and diversity are necessary for creativity. The future builds on the past but not with a one-to-one relationship, so there is more than one possible future. During change, new features emerge which could not have been predicted. In addition, "Systems which are diverse, richly-connected and open to their environments can evolve form through the way connections are synergistic or antagonistic: such forms may be more harmoniously in tune with their surroundings than what was there before and hence prosper; or they may be less tuned to the context, and hence may disappear[10]." This view led economists, such as Boulding [11], to question the traditional linear model and assumptions of neo-classical economic models. Thus we see the need for policy makers and strategists to incorporate the new understandings of an interconnected world-view. Any solutions to challenges must incorporate diverse perspectives and consider the interconnectedness of multiple aspects, and economic considerations cannot be separated from other considerations. Nature, existing institutions and communities must all be considered [12]. This viewpoint would support a bio-centric 
worldview. An example of governance and reporting from this perspective follows.

\section{Governmentally Required Holistic Reporting}

The Maori, indigenous peoples in New Zealand, share a holistic or unified world-view with many eastern philosophies and other indigenous peoples. The Maori tribal worldview acknowledges spiritual and human ancestors and descendants as intrinsic and prioritizes holistic well-being and value creation over profit maximization. The Maori work from a notion of the collective will. Maori-culture-society defines four well-beings: 1) spiritual well-being; 2) ecological well-being; 3) kinship well-being; and finally 4) economic well-being. Their view is congruent with that espoused by other indigenous groups and is seen clearly in the literature on "indigeneity" that is a critical part of discussions on natural and social sustainability [13]. We take the Maori example because in 1987, the New Zealand government recognized their bio-centric world view and required reporting to that view. The Department of Conservation (DOC) is a public benefit entity established under the 1987 Act. It is charged with the "preservation and protection of natural and historic resources for the purposes of maintaining their intrinsic values, providing for their appreciation and recreational enjoyment by the public, and safeguarding the option of future generations [14]."

This view acknowledges the importance of biodiversity and understanding ecosystems. In planning, policy and reporting, impacts on air, water, and soil, and diversity of both plant and animal life are to be considered. This orientation contrasts with the anthropocentric world-view that privileges mankind above all other species and is held to have led to environmental degradation [15] [16] [17]. In their research, Samkin and Schneider stated the following, "Human activities including the industrial revolution, population explosion, the rise of a global exchange economy, colonization, plantation agriculture and deforestation, mining as well as poaching have contributed to environmental and ecosystem degradation resulting in species and biodiversity loss[18]."

A holistic view includes the notion of "intrinsic value". This tenet is a component of global conservation efforts and is part of the governance model adopted in New Zealand, where the intrinsic value of natural resources is specifically recognized in the 1987 Act. The 1987 Act, with its charge to preserve and protect the intrinsic value of the natural resources, is seen to take a non-anthropocentric or deep ecology view. Following the deep ecology approach, Samkin and Schneider analysed required annual reports of the New Zealand Department of Conservation (DOC) using the framework developed, and their published article is the basis of our discussion. The authors state that deep ecology is linked with "intrinsic values as well as the normative principle of self-realization to indigenous cosmogony". Their study substantiates the deep ecology perspective taken. The two core principles noted are bio-centrism and self-realization.

Bio-centrism has four core beliefs: 1) all life is interdependent; 2) all species have intrinsic value; 3 ) humans do not have a privileged role in the biosphere; and 4) humans are not inherently superior to other species. The second principle, self-realization, is conceived as reconciling spirit and matter, human and nonhuman. This is seen by Devall and Sessions [19] as "consistent with the tenets of Native American spirituality as well as a number of eastern religions and philosophies such as Buddhism, Taoism and Hinduism." Analysis of the DOC annual reports is based on the framework developed from the deep ecology platform of Naess and Sessions [20]. The platform includes intrinsic value, diversity, vital needs, population, human interference, policy change, quality of life and obligation of action. This framework can be used to examine reporting by the DOC.

Adding to the discussion of Maori worldview above is the discussion of Maori values used specifically by Samkin and Schneider in their study.

The aboriginal inhabitants of New Zealand, Maori, have a holistic view of the environment and its indigenous biodiversity. Both are integral to their world-view because as kaitiaki (guardians), Maori believe they have a special role and responsibilities. It is derived from a cosmogony (belief system) that links people and all living and non-living things. This cosmogony is fundamental to the wellbeing of the Maori. Not only does it provide the connection to mythologize cosmic forces, but also links ecosystems to the source of personal life. Extending this cosmogony and central to the protection of the natural environment is the concept of kaitiakitanga.

The authors further note that Maori guardianship extends to the protection of the language, culture and wisdom as well as nature.

The DOC is the governance entity charged with responsibility for policy implementation and reporting. Annual reports from 1988 to 2010 were examined using content analysis. The annual reports were classified using three categories: 1) strategic planning, 2) performance / implementation, and 3) evaluation. This reporting is part of the accountability to the public. Samkin and Schneider's analysis of these reports gives insight into the potential for governance and reporting to impact significant challenges. The reported results show some change in emphasis over time as objectives and targets evolved, but were consistent with the objective of preserving the natural and historical heritage of New Zealand for present and future generations. Recognition is made of the "importance of biodiversity for its tangible and intangible or spiritual benefits in annual reports from 2004."

The DOC, a public benefit entity, is charged with developing appropriate strategy, implementation and evaluation for the stewardship of natural resources. The 
DOC goals are found to be congruent with a deep ecology classification. The department works from its mandate to encompass the Maori world-view which includes the requisite variety seen for adaptation in complex adaptive systems. The mandate allows the department to protect biodiversity as well as to provide appropriate access for recreational use. Challenges inevitably arise over tensions between these responsibilities. Reporting over the study years evidenced a shift from protection of cute, furry or impressive species in earlier years to protection of diverse ecosystems in later years. The bio-centric view recognizes "intrinsic value". The DOC website provides corporate reports which include the annual report and a statement of intent. The focus on bio-diversity and preservation of requisite variety is seen in reports of specie preservation and habitat restoration.

The adoption of the Maori world-view allows for strategy development and implementation on a different dimension. From a bio-centric perspective, all species, and indeed all geological features, have acknowledged intrinsic value. Thus strategy can be developed and implemented for the protection and restoration of species and habitat regardless of commercial value. DOC corporate reports evaluate and document these efforts. These goals and outcomes are reported annually and tracked over time. These complex ecosystems can be monitored and adaptation observed. Following CAS theory, small changes can have disproportionately large effects. The reporting feedback loop in this process allows for positive correction. Monitoring allows for early correction of negative unintended consequences.

Thus we see that governance and reporting in this New Zealand example are part of the response to present-day challenges. The adoption of a unified world-view allows these challenges to be addressed using strategy that is nonlinear, holistic and adaptive. In addition to New Zealand, other governments have supported a holistic world-view. Examples are Ecuador, which has written it into their constitution, and Bolivia, which explicitly grants rights to "nature".

\section{Not-For-Profit Required Governance Reporting}

Nonprofit organizations exist to better the physical, cultural and social wellbeing of society. Because their missions are directed toward the public good, it could be argued these organizations automatically fall into the holistic model, working for sustainability and accountability. However, theoretical researchers have argued that, in the absence of owners, nonprofit managers may seek private advantage in such forms as excess compensation, perquisites and responsibility shirking [21], [22]. Empirical research has established links between nonprofit oversight and desirable social comes. As examples, Olson [23] showed that increases in size, average tenure and level of executive business background of board members were associated with better nonprofit performance. Callen, Klein \& Tinkelman[24] established a link between better board oversight and percentage of total expenses used for mission support. Fisman and Hubbard [25] and Desai and Yetman[26] studied the oversight role of governments and found that manager compensation is negatively associated with strong oversight while funds designated for permanent endowments are positively associated with strong oversight. Finally, Yetman and Yetman[27] found the quality of financial reporting was positively associated with having a financial audit.

Therefore, although the raison d'etre of nonprofits may be to benefit society, reporting plays an important role in guaranteeing that the organization's resources are directed towards its stated purposes. We cite, as one example, the reporting requirements for nonprofit organizations in the United States. US entities are granted tax-exempt status by the government if they demonstrate a charitable or other public purpose. Once granted tax-exempt status, organizations are required to file an annual information return, Form 990, with the Internal Revenue Service (IRS). The IRS takes the position that organizations receiving tax benefits have a duty of care to use resources to support their tax-exempt missions, and the Form 990 is a mechanism whereby the IRS and the general public can monitor nonprofit stewardship.

The Form 990 requires organizations to provide detailed information on a comprehensive list of items including, but not limited to the organization's mission, major programs, services provided, financial statements, major donors, executive compensation and governance practices. Nonprofit entities must file this information with the IRS and are also required by law to make it available to the public each year.

In 2008, the IRS introduced a significant revision of the Form 990 in response to calls from both government and the public for more transparency and accountability in the US nonprofit sector. A key element of the drive for more transparency and accountability was the addition of a separate governance section in the revised 990. The importance placed on the governance section was clearly indicated by the IRS. Speaking in 2008 on the initiative to foster better nonprofit governance, Commissioner Steve T. Miller of the IRS stated, "The crown jewel of this effort is the governance section of the Revised Form 990[28]."

The new governance section is entitled Part VI: Governance, Management and Disclosure. Part VI is divided into three sections: 1) Governing Body and Management, 2) Organizational Policies, and 3) Disclosure.

The Governing Body and Management section deals primarily with practices of the governing board such as independence of board members, board size, documentation of board meetings and business, etc. The Policies section requires organizations to disclose if they have adopted certain policies (such as conflict of interest, whistleblower 
and document retention) and procedures (such as board review of the Form 990 before filing and determining reasonable officer compensation) in place. The Disclosure section requires organizations to report if and how they make organizational documents available to the public, including the Form 990, audited financial statements and governing documents.

Although some governance information was included in earlier versions of Form 990, the 2008 revision significantly expanded the amount of governance information provided. This allows various stakeholder groups to arrive at better-informed opinions about nonprofit organizations of interest. For example, governments can use the information to decide where to focus audits and investigations, potential donors can decide where to allocate their charitable giving, and private foundations can use the information when making grant allocations.

Although the IRS requires reporting on governance, management and disclosure practices, it does not mandate governance particulars. Practice varies widely in terms of board size, independence, and structure just as organizations vary widely in terms of mission, purpose, programs, size and complexity. But developments in the aftermath of the Form 990 Revision suggest that reporting matters. We cite evidence from two sources that reporting matters. First, charity watchdog groups are using the governance information from the 990 to create governance scores to help the public assess the strength of a nonprofit's governance regime. For example, after 2008, Charity Navigator began publishing an "Accountability and Transparency" score for each of the several thousand charities it rates. Explaining its methodology for calculating the score on its website, Charity Navigator states, "The IRS expanded the Form 990 in 2008 to collect additional information from charities that can accept tax-deductible donations. Several changes were designed to inform the public about potential conflicts of interest, board oversight, executive compensation, and record keeping. 12 of the 17 Accountability \& Transparency categories that we analyze are collected from the expanded Form 990[29]."

And in a recent study, researchers surveyed nonprofit managers to document the impact of heightened reporting on nonprofit practices [30]. Specifically, nonprofit managers provided information about 16 governance items that were newly included on the revised Form 990 . Survey participants were asked whether the 16 practices existed in their organizations before the adoption of the revised Form 990 and whether the practices exist today. The 16 practices are:

1. Are all members of the governing board independent?

2. Are any management duties outsourced?

3. Are board meetings documented at the time meetings are held?

4. Are board committee meetings documented at the time meetings are held?

5. Does the governing board review the Form 990 before it is filed?
6. Are trustees, officers, directors and key employees required to disclose conflicts of interest annually?

7. Is there regular monitoring of a conflict of interest policy?

8. Is there regular enforcing of a conflict of interest policy?

9. Does the organization have a written whistleblower policy?

10. Does the organization have a written document retention and destruction policy?

11. Is CEO compensation approved by independent persons?

12. Is comparative data used in determining CEO compensation?

13. Is the process of determining CEO compensation substantiated and documented?

14. Is other officer compensation approved by independent persons?

15. Is comparative data used in determining other officer compensation?

16. Is the process for determining other officer compensation substantiated and documented?

For all 16 practices, the percentage of nonprofits that included the practice in their governance regimes increased from the before to the after period. And t-tests for differences in the before and after percentages was significant for nine out of the 16 measures. Therefore, the Form 990 reporting requirements on governance of nonprofits in the U.S. provide another example of governance and reporting mechanisms that can help meet the challenges of our times.

\section{Board Governance and Reporting in a Publicly Traded Corporation}

Corporate as well as not-for-profit boards give guidance and direction which management then implements and reports on. Successful implementation requires leadership and support from the highest level. In the following discussion, the public reporting of a Fortune 100 firm is presented as representative of the current state of disclosure and accountability. We have chosen Intel's 2008 Corporate Responsibility Report because it covers a time when Intel was recognized for its leadership in corporate responsibility. We also consider related documents that Intel makes publicly available: their Values Statement, Code of Conduct and Corporate Principles for Responsible Business. These documents represent a public articulation of the company's values, culture and expectations and provide the context within which governance is carried out and accountability is achieved. We base the following discussion on the work of Dillard and Layzell [31], [32] who undertook an in-depth analysis of the evolution of corporate social responsibility (CSR) within the company and how it became embedded within the current corporate structure. Leadership for this effort came from the board chair and CEO of the company. 
The strategic move to embed CSR in corporate policy was then implemented by management and reported in publicly available documents.

Dillard and Layzell [32] outline four categories that reflect interrelated and, at times, contradictory forces that comprise the matrix of responsibility confronting a publicly held enterprise. Each category represents a constituency group and can be represented by a set of responsibilities, or demands, that the corporation must consider:

1. Corporate values - Who do we want to be?

2. Fiscal responsibility - What is in the best interests of the shareholders?

3. Stakeholder expectations - Who do they want us to be?

4. Compliance - What does the law and society expect?

These dimensions provide a context wherein Dillard and Layzell consider the public representations of what the company considers to be its corporate responsibilities and how it has chosen to fulfill these responsibilities.

The 2008 Corporate Responsibility Report was 107 pages in length and was published both on line and in hard copy. The first three sections of the report address the question: "Who are we?" and the next five sections address the question: "What are we doing?" Quantitative as well as qualitative information is provided, and actual performance is compared with targets. The report identifies four key areas: 1) the environment; 2) health and safety; 3) education; and 4) workplace diversity.

The board and top management specify the parameters for action through the values and code of conduct, which provides the context for interacting with the various interested groups and attempting to ameliorate the related conflicting demands. The values, basically unchanged since they were recorded in 1986, guide the company's actions. In addition to other orientation activities, every new employee receives training regarding the Intel culture and values.

The code of conduct attempts to articulate, in universally understandable terms, a link between the value statement and day-to-day practical business decisions. Dillard and Layzell observe that related guidelines, training, and other learning aids supplement and interpret the code of conduct, reinforcing the themes of compliance, culture, and fiscal responsibility. The authors conclude that throughout these documents "the company clearly states its commitment to stockholders by its unequivocal support for the principles of market capitalism and the primacy of maximizing long-term shareholder value."

After reviewing the company's report, Dillard and Layzell consider the report in light of the various competing tensions confronting publicly held entities (e.g., corporate values, fiscal responsibility, stakeholder expectations, and compliance). The company's motivations and intentions are generally articulated, and they seem to attempt to be reasonably transparent unless what they consider proprietary information is involved.

Dillard and Layzell conclude that there is little question as to the dominance of the business case for corporate responsibility. The following quote from the President and CEO Paul Otelline reflects the company's overall position: "Making corporate responsibility an integral part of Intel's strategy helps us mitigate risk, build strong relationships with our stakeholders, and expand our market opportunities [33]." The economic dimension and shareholders are the primary focus. The other responsibilities are embraced as they support economic performance.

In summary, some concept of corporate responsibility has been an integral component of Intel's corporate governance. Dillard and Layzell's analysis concludes that while discussed within the context of people, community and the environment, all activities are directly or indirectly related to a business purpose. Intel's governance strategy privileges shareholder value maximization. The authors summarized the governance strategy as the ordering of the following questions.

1. What is the most economically advantageous alternative?

2. How might it be achieved in the most sustainable manner?

Economic gains are privileged with respect to corporate governance criteria. Although stakeholders are attracting more attention, the competing demands on the company continue to privilege fiscal dimensions, and the tenets of global market capitalism define the parameters of corporate responsibility. We find this to be a business example of a strategic adaptation in the global complex environment. Both governance leadership and reporting were key components of this corporate response to change.

\section{Conclusions}

In this paper, three disparate examples of governance and reporting provide insight into possible mechanisms for meeting the complex challenges faced by all corporate entities at this time. The very different examples presented demonstrate corporate governance and reporting can be an effective mechanism in adapting to global societal needs. In a worldview that is holistic, bio-centric and cultural value based we see that monitoring and reporting led to changes in viewpoint and thus to changes in strategic policy implementation. The Maori example from the Asia-Pacific region provides a societal level exemplar as well as a nonlinear understanding of complex reality and interrelatedness. Tensions between competing values call for adaptive approaches when resolving challenges in social, economic and environmental decision-making and strategic planning. Competing values call for the inclusive nonlinear possibilities seen in the complex adaptive systems models as well as the corporate governance models of profit-driven corporations.

As some societal needs are met through allocation of resources to the nonprofit sector, governance, reporting and accountability again are critical to effective decision and 
response. The rating schemes used to evaluate nonprofits arise in part from the mandatory reporting requirements in the 990 form. Thus the institutions in the US achieving nonprofit status are evaluated on their governance. Monitoring and financing choices effectively follow the reporting. The role of governance and reporting is quite clear in the required reporting initiated in the U.S. tax code and the New Zealand Conservation Act.

The adaptive impact of governance and voluntary reporting in the public for profit sector is evidenced in the Intel example. A major for-profit corporation responded to its complex business environment by developing additional environmental reporting and incorporating it into the reporting of the corporation. Thus, at the level of the firm, mechanisms for governance and reporting can be utilized to meet emerging challenges.

Globally, governance guidelines such as those provided by the $\mathrm{OECD}[34]$ for state owned enterprises and multinational corporations are universally available. Reporting models such as those provided by the GRI[35], SA 8000[36] and AA1000[37] are also available for public use worldwide. Thoughtful governance and reporting, whether mandatory or voluntary, provide for adaptive response in a complex environment and accountability to communities both local and global.

\section{REFERENCES}

[1] Mukherji P, Sengupta, C. Indigeneity and universality in social science. Mukerji and Sengupta, editors. New Delhi/Thousand Oaks/London: Sage Publications; 2004.

[2] Schumacher, E. Small is beautiful: Economics as if people mattered. London: Blond \& Briggs; 1973.

[3] Daly H, Cobb J. For the common good: Redirecting the economy toward community, the environment and a sustainable future. London: Beacon Press; 1989.

[4] Gray R. Thirty years of social accounting, reporting, and auditing: what (if anything) have we learnt? Business Ethics: A European Review. 2001; 10(1):9-15.

[5] Gray R. Social and environmental accounting and reporting: from ridicule to revolution? From hope to hubris? - A personal review of the field. Issues in Social and Environmental Accounting. 2008; 2(1):3-18.

[6] Mathews M. Twenty-five years of social and environmental accounting research: is there a silver jubilee to celebrate? Accounting, Auditing \& Accountability Journal. 1997; $10(4): 487-531$.

[7] Bebbington J. Sustainable development: A review of the international development, business and accounting literature. Accounting Forum. 2001; 25 (2):128-156.

[8] Bebbington J, Larringa C, Moneva J. Corporate social reporting and reputation risk management. Accounting, Auditing \& Accountability Journal. 2008; 21(3):337-361.
[9] Tricker B. Corporate governance principles: Policies and practices. London: Oxford University Press; 2012.

[10] Boulton J. Complexity theory and implications for policy development. Emergence: Complexity and Organization. 2010; 12(2):31-40.

[11] Boulding K. A reconstruction of economics. New York: Wiley; 1959.

[12] Korten D. When corporations rule the world. Boulder: Kumarian Press; 1995.

[13] Harris L. Wasilewski J. Indigeneity, an alternative worldview: Four R's (relationship, responsibility, reciprocity, redistribution) vs. two P's (power and profit), sharing the journey towards conscious evolution. Systems Research and Behavioral Science. 2004: 21(5):489-503.

[14] New Zealand. Conservation Act 1987. Public Act No 65. Available from: www.legislation.govt.nz/act/public/1987/00 65/latest/whole.html.

[15] Machlis G. The contribution of sociology to biodiversity research and management. Biological Conservation. 1992; 62(3):161-170.

[16] Jones M. Accounting for biodiversity: operationalizing environmental accounting. Accounting, Auditing, and Accountability Journal. 2003; 16(5):762-789.

[17] Diaz S, Fargione J, Chapin F, Tillman D. "Biodiversity loss threatens human wellbeing. PLoS Biology. 2006; 4(8):1300-1305.

[18] Samkin G, Schneider A. Developing a reporting and evaluation framework for biodiversity. Accounting, Auditing \& Accountability Journal. 2014; 26(3):526-562.

[19] Devall B, Sessions G. Deep ecology. Salt Lake City, UT: Peregrine Smith; 1985.

[20] Naess A, Sessions G. Basic principles of deep ecology. Ecophilosophy. 1984; 6:3-7.

[21] Jensen M, Meckling W. Theory of the firm: Managerial behavior, agency costs, and ownership structure. Journal of Financial Economics.1976; 3(4):305-360.

[22] Fama E, Jensen M. Agency problems and residual claims. Journal of Law \& Economics. 1983; 26:301-325.

[23] Olson D. Agency theory in the not-for-profit sector: Its role at independent colleges. Nonprofit \& Voluntary Sector Quarterly. 2000; 29:280-296.

[24] Callen J, Klein A, Tinkelman D. Board composition, committees, and organizational efficiency: The case of nonprofits. Nonprofit and Voluntary Sector Quarterly. 2003; 32(4):493-520

[25] Fisman R, Hubbard R. "Precautionary savings and the governance of nonprofit organizations. Journal of Public Economics. 2005; 89(11):2231-2243.

[26] Desai M, Yetman R. Constraining managers without owners: governance of the not-for-profit enterprise. 2006. NBER Working Paper No. 11140.

[27] Yetman M, Yetman, R. "The effects of governance on the accuracy of charitable expenses reported by nonprofit organizations. Contemporary Accounting Research. 2012; 29(3):738-767 
[28] Miller S. Remarks at the western conference on tax exempt organizations on November 20, 3008. Available from: http://www.irs.gov/pub/irs-tege/stm/loyolagovernance_1120 8.pdf

[29] Charity Navigator [content page on the Internet]. No date. Available from: http://www.charitynavigator.org/index.cfm?bay=content.vie w\&cpid=1093\#.Vf2gFUtvbfM.

[30] Richards C, Eining M, Hurtt K. Did the revised Form 990 improve nonprofit governance and disclosure practices? Working paper, Zayed University. 2015.

[31] Dillard J, Layzell D. Social sustainability—one company's story. In: Dillard J, King $\mathrm{M}$, Dujon $\mathrm{V}$, editors. Understanding the social dimension of sustainability. Taylor \& Francis, 2009; p.174-198.
[32] Dillard J, Layzell D. An ongoing journey of corporate social responsibility. Accounting Forum. 2014; 38:212-226.

[33] Intel. The code of conduct. 2007. Available from http://download.intel.com/intel/finance/code-of-conduct.pdf.

[34] OECD. Principles of governance. 2014. Available from: http://www.oecd.org.

[35] GRI. Global reporting initiative guidelines G4. 2014. Available from: http://www.gri.org.

[36] Social Accountability International. SA8000 Standard. 2014. Available from: http://www.sa-intl.org.

[37] Accountability. Setting the Standard for Corporate Responsibility and Sustainable Development. 2014. Available from: www.accountability.org/standard/. 